\title{
No evidence for association of insulin receptor substrate-1 Gly972Arg variant with type 2 diabetes mellitus in a mixed-ancestry population of South Africa
}

\author{
Z Vergotine,${ }^{1,2}$ MSc; A P Kengne, ${ }^{3}$ MD, PhD; R T Erasmus, ${ }^{2}$ FCPath; T E Matsha, ${ }^{1} \mathrm{PhD}$ \\ ${ }^{1}$ Department of Biomedical Sciences, Faculty of Health and Wellness Sciences, Cape Peninsula University of Technology, Cape Town, South Africa \\ ${ }^{2}$ Division of Chemical Pathology, Faculty of Medicine and Health Sciences, Stellenbosch University, Tygerberg, Cape Town, South Africa \\ ${ }^{3}$ National Collaborative Research Programme for Cardiovascular and Metabolic Diseases, South African Medical Research Council, Tygerberg and \\ University of Cape Town, South Africa
}

Corresponding author: T E Matsha (matshat@cput.ac.za)

Background. The most common single-nucleotide polymorphism in the insulin receptor substrate-1 (IRS1) gene is Gly972Arg, which is associated with a $25 \%$ increased risk of developing diabetes. The mixed-ancestry population of South Africa (SA) has one of the highest prevalences of type 2 diabetes mellitus (T2DM) in Africa.

Objective. To report the frequency of IRS1 Gly972Arg and investigate its associations with cardiometabolic traits.

Methods. DNA from 856 mixed-ancestry adults drawn from an urban community of Bellville South, Cape Town, SA, was genotyped by two independent laboratories. Oral glucose tolerance tests were performed and cardiometabolic risk factors measured.

Results. A total of 237 (24.7\%) participants had T2DM. The IRS1 Gly972Arg variant was present in $7.9 \%$ of the individuals studied and only one participant (non-diabetic) carried the homozygous A/A variant. In linear and logistic regression analyses, Gly972Arg was not associated with obesity, insulin resistance/sensitivity or T2DM.

Conclusions. The prevalence of the Gly972Arg variant in the mixed-ancestry population of SA is comparable to that reported in African Americans, but its presence is not associated with cardiometabolic traits. This suggests that the Gly972Arg variant may not aid diabetes risk evaluation in this setting, nor can such information help explain the high prevalence of diabetes previously reported in this population.

S Afr Med J 2014;104(6):420-423. DOI:10.7196/SAMJ.7419

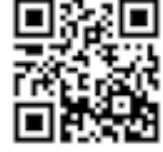

Insulin receptor substrate-1 (IRS1) is a wellcharacterised intracellular substrate for insulin receptor tyrosine kinases containing Src homology 2 (SH2) domains, e.g. phosphatidylinositol 3-kinase, growth factor receptor-bound protein 2 and $\mathrm{SH} 2-$ containing protein tyrosine phosphatase in the insulin-signalling

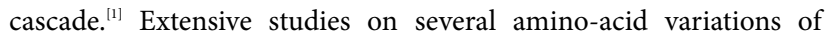
the IRS1 gene have shown associations with human metabolic disorders such as type 2 diabetes mellitus (T2DM), ${ }^{[2]}$ obesity $^{[3]}$ and insulin resistance in various population studies as well as in animal models. ${ }^{[4]}$ Gly972Arg (rs1801278) is the most studied singlenucleotide polymorphism (SNP) of the IRS1 gene because it is a functional mutant reported to impair insulin signalling in transfected cell lines and in human cells carrying the variant. ${ }^{[5-7]}$ There are no data currently available for populations in Africa.

Therefore, our study objective was to determine the frequency of Gly972Arg and investigate its associations with T2DM, insulin resistance and obesity traits in the mixed-ancestry population of South Africa (SA), which has been found previously to be prone to diabetes. ${ }^{[8]}$

\section{Methods}

\section{Study setting and population}

The study setting, survey design and procedures have been described in detail elsewhere. ${ }^{[8,9]}$ Briefly, eligible participants were invited to take part in a community-based survey from January 2008 to March
2009 (cohort 1), and January to November 2011 (cohort 2) in Bellville South, Cape Town, SA. The study was approved by the research ethics committees of Stellenbosch University and the Faculty of Health and Wellness Sciences, Cape Peninsula University of Technology. All participants gave written informed consent after all the procedures were fully explained in the language of their choice.

\section{Clinical data}

All consenting participants received a standardised interview and physical examination during which blood pressure (BP) was measured according to the World Health Organization (WHO) guidelines ${ }^{[10]}$ using a semi-automated digital BP monitor (Rossmax, USA) on the right arm in a sitting position. Other clinical measurements included body weight, height, and waist and hip circumferences. All anthropometric measurements were performed three times and results averaged. Participants with no history of doctor-diagnosed diabetes underwent a $75 \mathrm{~g}$ oral glucose tolerance test (OGTT) as recommended by the WHO. ${ }^{[11]}$

\section{Laboratory measurements}

Blood samples were collected after an overnight fast and processed for further biochemical analysis. Plasma glucose was measured using the enzymatic hexokinase method, and glycated haemoglobin (HbAlc) by turbidimetric inhibition immunoassay (Cobas 6000, Roche Diagnostics, Germany). Total cholesterol (TC), highdensity lipoprotein cholesterol (HDL-C), and triglycerides (TGs) 
were estimated by enzymatic colorimetric methods (Cobas 6000 , Roche Diagnostics, Germany). Low-density lipoprotein cholesterol (LDL-C) was calculated using Friedewald's formula. ${ }^{[12]}$ Insulin was determined using a microparticle enzyme immunoassay (Axsym, Abbott, USA).

\section{SNP genotyping}

Genomic DNA was extracted from whole-blood samples collected in an EDTA tube. For quality control purposes, genotyping for IRS1 Gly972Arg (rs1801278) was carried out in two independent laboratories on the ABI Prism 7900HT platform (Applied Biosystems, USA) and a BioRad Optica (BioRad, USA) using Taqman genotyping assay (Applied Biosystems, USA). In all but two cases, there was complete agreement concerning the genotypes. Consensus agreement was achieved by the comparisons of raw data outputs and automated sequencing using ABI 3730.

\section{Definitions}

Body mass index (BMI) was calculated as weight (in $\mathrm{kg}$ ) $/ \mathrm{m}^{2}$ and waist-to-hip ratio as waist/hip circumferences (in $\mathrm{cm}$ ). Diabetes status was based on a history of doctor diagnosis, a fasting plasma glucose $\geq 7.0 \mathrm{mmol} / \mathrm{l}$ and/or a 2-hour post-OGTT plasma glucose $\geq 11.1 \mathrm{mmol} / \mathrm{l}$. The following calculations were used:
- homeostatic model assessment of insulin resistance (HOMA-IR) $=[$ fasting insulin concentration $(\mu \mathrm{IU} / \mathrm{l}) \times$ fasting plasma glucose $(\mathrm{mmol} / \mathrm{l})] \div 22.5$

- functional $\beta$-cells $(\mathrm{HOMA}-\beta \%)=[20 \times$ fasting insulin $(\mu \mathrm{IU} / \mathrm{ml})] \div$ [fasting glucose $(\mathrm{mmol} / \mathrm{ml})-3.5$ ]

- fasting insulin resistance index $($ FIRI $)=[$ fasting insulin $(\mu \mathrm{U} / \mathrm{ml}) \times$ fasting glucose $(\mathrm{mM})] \div 25$

- quantitative insulin-sensitivity check index (QUICKI) $=1 \div$ $\left[\log (\text { fasting insulin }(\mu \mathrm{U} / \mathrm{ml}) \times \log (\text { fasting glucose }(\mathrm{mg} / \mathrm{dl}))]^{[13]}\right.$

\section{Statistical analyses}

Of the 1256 participants who took part in the survey, 1035 consented to genetic studies. Among the latter, 126 were excluded because they were related to the other participants, and 53 were excluded owing to missing data on the genetic or T2DM trait variables. Therefore, 856 had valid data for the current analyses. General characteristics of the study group were summarised as $n$ and $\%$ for dichotomous traits, and mean \pm standard deviations (SDs) or median and 25th - 75th percentiles for quantitative traits. Traits were log-transformed to approximate normality, where necessary, prior to analysis. SNPs were tested for departure from Hardy-Weinberg Equilibrium (HWE) via a $\chi^{2}$ goodness-of-fit test. Linear regression

Table 1. General characteristics of the overall population by diabetic status

\begin{tabular}{|c|c|c|c|c|}
\hline & Overall & No diabetes & Diabetes & $p$-value \\
\hline Patients, $n$ & 856 & 619 & 237 & \\
\hline Gender (male), $n$ & 235 & 51 & 184 & 0.83 \\
\hline Age (years), mean $( \pm \mathrm{SD})$ & $53.4( \pm 15.4)$ & $51.0( \pm 15.5)$ & $50.6( \pm 13.5)$ & $<0.0001$ \\
\hline \multicolumn{5}{|l|}{ Clinical, mean $( \pm S D)$} \\
\hline Systolic BP (mmHg) & $125( \pm 21)$ & $123( \pm 19)$ & $130( \pm 23)$ & $<0.0001$ \\
\hline Diastolic BP (mmHg) & $76( \pm 13)$ & $75( \pm 12)$ & $77( \pm 15)$ & 0.07 \\
\hline BMI $\left(\mathrm{kg} / \mathrm{m}^{2}\right)$ & $29.9( \pm 7.2)$ & $29.3( \pm 7.1)$ & $31.7( \pm 7.1)$ & $<0.0001$ \\
\hline Waist circumference $(\mathrm{cm})$ & $96( \pm 15)$ & $95( \pm 15)$ & $102( \pm 14)$ & $<0.0001$ \\
\hline Hip circumference $(\mathrm{cm})$ & $109( \pm 14)$ & $109( \pm 14)$ & $111( \pm 15)$ & 0.04 \\
\hline Waist-to-hip ratio & $0.88( \pm 0.10)$ & $0.87( \pm 0.10)$ & $0.92( \pm 0.08)$ & $<0.0001$ \\
\hline \multicolumn{5}{|l|}{ Laboratory } \\
\hline HbAlc $(\%)$, mean $( \pm S D)$ & $6.3( \pm 1.5)$ & $5.7( \pm 0.4)$ & $7.8( \pm 2.1)$ & $<0.0001$ \\
\hline $\mathrm{HbAlc}(\mathrm{mmol} / \mathrm{mol})( \pm \mathrm{SD})$ & $45.4( \pm 16.4)$ & $38.8( \pm 4.4)$ & $61.7( \pm 23.0)$ & $<0.0001$ \\
\hline Fasting blood glucose $(\mathrm{mmol} / \mathrm{l})$, mean $( \pm \mathrm{SD})$ & $6.4( \pm 3.1)$ & $5.1( \pm 0.7)$ & $9.6( \pm 4.3)$ & $<0.0001$ \\
\hline 2-hour plasma glucose $(\mathrm{mmol} / \mathrm{l})$, mean $( \pm \mathrm{SD})$ & $7.5( \pm 3.6)$ & $6.4( \pm 1.6)$ & $13.4( \pm 5.3)$ & $<0.0001$ \\
\hline $\mathrm{TG}(\mathrm{mmol} / \mathrm{l})$, mean $( \pm \mathrm{SD})$ & $1.5( \pm 0.9)$ & $1.4( \pm 0.9)$ & $1.7( \pm 0.9)$ & $<0.0001$ \\
\hline HDL-C $(\mathrm{mmol} / \mathrm{l})$, mean $( \pm \mathrm{SD})$ & $1.3( \pm 0.4)$ & $1.3( \pm 0.4)$ & $1.2( \pm 0.3)$ & $<0.0001$ \\
\hline LDL-C $(\mathrm{mmol} / \mathrm{l})$, mean $( \pm \mathrm{SD})$ & $3.6( \pm 1.0)$ & $3.6( \pm 1.0)$ & $3.7( \pm 1.1)$ & 0.14 \\
\hline $\mathrm{TC}$, mean $( \pm \mathrm{SD})$ & $5.6( \pm 1.2)$ & $5.5( \pm 1.2)$ & $5.7( \pm 1.3)$ & 0.06 \\
\hline Insulin, median ( $25-75$ th percentile) & $7.5(3.4-13.8)$ & $6.9(3.3-12.5)$ & $10.2(4.4-17.6)$ & $<0.0001$ \\
\hline 2-hour insulin, median (25 - 75th percentile) & $37.1(19.5-73.0)$ & $35.1(19.2-63.5)$ & $62.3(24.3-118.7)$ & $<0.0001$ \\
\hline Glucose/insulin, median ( 25 - 75 th percentile) & $0.74(0.42-1.63)$ & $0.72(0.41-1.51)$ & $0.78(0.47-2.05)$ & 0.10 \\
\hline HOMA-IR, median (25 - 75th percentile) & $1.9(0.8-3.8)$ & $1.6(0.7-2.9)$ & $3.6(1.6-7.3)$ & $<0.0001$ \\
\hline HOMA- $\beta$ (\%), median (25 - 75th percentile) & $72.7(30.9-146.5)$ & $90(41.8-162)$ & $44.5(13.5-81.7)$ & $<0.0001$ \\
\hline QUICKI, median (25 - 75th percentile) & $0.15(0.14-0.17)$ & $0.15(0.14-0.18)$ & $0.14(0.12-0.15)$ & $<0.0001$ \\
\hline FIRI, median (25 - 75th percentile) & $1.69(0.75-3.39)$ & $1.4(0.6-2.6)$ & $3.2(1.4-6.6)$ & $<0.0001$ \\
\hline 1/HOMA-IR, median (25 - 75th percentile) & $0.53(0.26-1.20)$ & $0.64(0.34-1.49)$ & $0.28(0.14-0.63)$ & $<0.0001$ \\
\hline
\end{tabular}


models were used for the analysis of quantitative traits and logistic regression models for dichotomous traits, always assuming additive models for the SNPs. We investigated the additive allelic association of Gly972Arg with each trait, overall and according to diabetes status, and tested for heterogeneity by adding the interaction term of diabetes and Gly972Arg to a model that contained the main effects of diabetes and Gly972Arg. A $p$-value $<0.05$ was considered significant. We did not adjust for multiple testing. All analyses were done with $\mathrm{R}$ (version 2.12.2).

\section{Power calculation}

Power calculation was performed with $\mathrm{CaTS},{ }^{[14]}$ assuming a diabetes prevalence of $28 \%,{ }^{[8]}$ a Gly972Arg frequency of $19 \%{ }^{[2]}$ a genotype odds ratio of $1.25^{[15]}$ under an additive model and a nominal $p$-value of $<0.05$. Based on the above, our population of 224 diabetic and 619 non-diabetic patients provided a statistical power of $60 \%$ for a onestage design.

\section{Results}

Clinical characteristics of participants according to diabetes status are summarised in Table 1; 237 (24.7\%) participants had T2DM. Compared with non-diabetic participants, those with diabetes had significantly higher adipometric variables (all $p \leq 0.04$ ), systolic BP $(p<0.0001)$ and TGs $(p<0.0001)$, whereas HDL-C levels were significantly lower $(p<0.0001)$.

Gly972Arg demonstrated HWE ( $p>0.05)$ according to gender and diabetes status. No significant differences in the genotype and allele distributions were observed between the study groups. The frequency distributions, both genotype and allele, did not differ significantly according to diabetes status or gender. The prevalence rate for the heterozygous variant ( $\mathrm{G}>\mathrm{A}, \mathrm{rs} 1801278)$ was $7.9 \%(n=68)$ overall, $6.7 \%(n=16)$ in diabetic and $8.4 \%(n=52)$ in non-diabetic participants. Only one participant (non-diabetic) carried the homozygous variant $(\mathrm{A} / \mathrm{A})$ with a corresponding A allele frequency of $4.1 \%$ overall, $3.4 \%$ in diabetic and $4.4 \%$ in non-diabetic participants. In linear regression analyses, IRS1 Gly972Arg was associated with none of the markers of glycaemia, insulin resistance or insulin sensitivity, both overall and in participants with and without diabetes taken separately, with no evidence of significant statistical interaction by diabetes status (all interaction $p \geq 0.30$ ), except for 2-hour glucose measurements where the effect size appeared to be greater among diabetic v. non-diabetic participants (interaction $p=0.19$ ) (Table 2). In logistic regression analyses, IRS1 Gly972Arg was not associated with prevalent diabetes after adjustment for age and sex, and after further adjustment for markers of insulin resistance/sensitivity, and markers of adiposity.

\section{Discussion}

Our study investigated the frequency of the IRS1 Gly972Arg variant in the mixed-ancestry population of SA. The overall prevalence of IRS1 Gly972Arg was $7.9 \%$, with a higher occurrence of the variant found in non-diabetics, and it was not associated with obesity, insulin resistance/sensitivity or T2DM. This suggests that knowledge of the the Gly972Arg variant status may not aid diabetes risk evaluation in this setting, and that it cannot explain the high prevalence of diabetes previously reported in this population.

Epidemiological studies on the association between the IRS1 Gly972Arg (rs1801278) SNP and various cardiometabolic traits have reported conflicting results. ${ }^{[2,3,15-19]}$ Although individuals carrying the Gly972Arg SNP have a 25\% increased risk of developing diabetes, ${ }^{[15]}$ genome-wide association studies involving subjects of European descent found no association between IRS1 and T2DM. ${ }^{[16,17]}$ Instead, a genetic variant, rs294361, located near IRS1 was associated with T2DM in a large-scale study of French and Danish individuals. ${ }^{[17]}$ Similarly, these associations have not been found ${ }^{[18]}$ in populations with a high prevalence of diabetes such as ours ${ }^{[8]}$ and Pima Indians. ${ }^{[20]}$ Jellema et al ${ }^{[15]}$ investigated some of these factors, including ethnicity, type of study, diagnostic test used to confirm the presence of diabetes, type of measurement of the polymorphism, prevalence of the polymorphism and age. These authors reported heterogeneity for type of study, diagnostic test used to exclude diabetes in the control subjects, and age of the case subjects as sources of inconsistency across studies. ${ }^{[15]}$

The majority of the studies, including ours, used populationbased designs that did not account for the gene-gene interaction phenomenon, defined as an interaction in which one gene suppresses or enhances the expression of another. For example, the protective effect against insulin resistance of the Ala allele Pro12Ala polymorphism in the peroxisome proliferator-activated receptor gamma $2(P P A R \gamma 2)$ gene was shown to be enhanced in the

Table 2. Generalised linear regression model of the phenotypic features for the at-risk allele $A^{*}$

\begin{tabular}{|c|c|c|c|c|c|c|c|}
\hline \multirow[b]{2}{*}{ Phenotype } & \multicolumn{2}{|c|}{ Overall } & \multicolumn{2}{|c|}{ No diabetes } & \multicolumn{2}{|l|}{ Diabetes } & \multirow[b]{2}{*}{$\begin{array}{l}\text { Interaction } \\
\text { ( } p \text {-value) }\end{array}$} \\
\hline & $\begin{array}{l}\text { Effects size } \\
(95 \% \mathrm{CI})\end{array}$ & $p$-value & $\begin{array}{l}\text { Effects size } \\
(95 \% \mathrm{CI})\end{array}$ & $p$-value & $\begin{array}{l}\text { Effects size } \\
(95 \% \mathrm{CI})\end{array}$ & $p$-value & \\
\hline Fasting glucose & $0.05(-0.56-0.62)$ & 0.86 & $0.12(-0.07-0.32)$ & 0.21 & $-0.16(-2.32-2.00)$ & 0.88 & 0.67 \\
\hline 2-hour glucose & $0.36(-0.28-1.01)$ & 0.27 & $0.06(-0.35-0.48)$ & 0.77 & $2.56(-1.26-6.38)$ & 0.19 & 0.01 \\
\hline HbAlc & $0.01(-0.27-0.28)$ & 0.95 & $0.02(-0.09-0.13)$ & 0.73 & $-0.02(-1.09-1.03)$ & 0.96 & 0.88 \\
\hline Fasting insulin & $-0.06(-4.35-4.22)$ & 0.98 & $-0.34(-2.87-2.18)$ & 0.79 & $0.64(-14.63-15.92)$ & 0.93 & 0.82 \\
\hline 2-hour insulin & $5.73(-11.05-22.51)$ & 0.50 & $2.20(-14.54-18.94)$ & 0.80 & $23.03(-33.94-80.01)$ & 0.43 & 0.30 \\
\hline Glucose/insulin & $-0.36(-2.76-2.05)$ & 0.77 & $-0.33(-2.35-1.68)$ & 0.75 & $-0.30(-7.78-7.18)$ & 0.94 & $>0.99$ \\
\hline HOMA-IR & $0.03(-1.77-1.84)$ & 0.97 & $-0.04(-0.64-0.56)$ & 0.89 & $0.12(-6.81-7.05)$ & 0.97 & 0.91 \\
\hline QUICKI & $-0.002(-0.01-0.01)$ & 0.70 & $-0.001(-0.02-0.01)$ & 0.88 & $-0.006(-0.03-0.01)$ & 0.54 & 0.73 \\
\hline FIRI & $0.03(-1.59-1.65)$ & 0.97 & $-0.04(-0.58-0.50)$ & 0.89 & $0.11(-6.13-6.35)$ & 0.97 & 0.91 \\
\hline
\end{tabular}

$\mathrm{CI}=$ confidence interval; HbAlc = glycated haemoglobin; HOMA-IR = homeostatic model assessment of insulin resistance; HOMA- $\beta$ = functional $\beta$-cells; QUICKI = quantitative insulin-sensitivity ${ }^{*}$ Models are adjusted for age, sex and presence of diabetes.
. 
presence of the IRS1 Gly972Arg variant. ${ }^{[2]}$ Insulin sensitivity was significantly greater in X/Ala $(P P A R \gamma 2)+\mathrm{X} / \mathrm{Arg}($ IRS1 Gly972Arg) than in Pro/Pro $(P P A R \gamma 2)+\mathrm{X} / \operatorname{Arg}$ (IRS1 Gly972Arg) carriers. ${ }^{[21]}$ Furthermore, a study that investigated the development of diabetes in mice with three mutations in the insulin receptor, IRS1 and IRS2 reported a higher prevalence $(40 \%)$ of progression to diabetes in mice with all three mutations compared with mice carrying one mutation $(5 \%){ }^{[22]}$

\section{Study strengths}

Our study included extensive data collection on a range of diabetes determinants, and is the first study to investigate the IRS1 Gly972Arg variant in an African population using two independent laboratories to genotype our study population.

\section{Study limitations}

The study was limited by the cross-sectional design. The sample size was small, so therefore replication of this analysis in a larger sample size is required to definitively rule out the association between IRS1 Gly972Arg and diabetes. We did not adjust for population stratification, as appropriate markers that can be used to map disease genes or correct for population stratification in the mixed-ancestry population are not yet available. Potential population stratification in unrelated samples may cause spurious positive or negative associations in population-based association studies. ${ }^{[23]}$ Insulin resistance was not based on the glycaemic clamp.

\section{Conclusion}

The prevalence of the Gly972Arg variant in the mixed-ancestry population of SA is comparable to that in African Americans (11.6\% in control subjects), ${ }^{[24]}$ but was not associated with obesity, insulin resistance/sensitivity or diabetes. The lack of association found between the IRS1 Gly972Arg variant and diabetes in this population study does not exclude its role in the gene-gene and geneenvironment interaction mechanisms underlying the pathogenesis of diabetes.

Acknowledgements. We thank the community of Bellville South, Cape Town, SA. This research was supported by grants from the University Research Fund of the Cape Peninsula University of Technology, the South African Medical Research Council, the Harry Crossley Foundation and Stellenbosch University.

\section{References}

1. Rocchi S, Tartare-Deckert S, Mothe I, van Obberghen E. Identification by mutation of the tyrosine residues in the insulin receptor substrate-1 affecting association with the tyrosine phosphatase $2 \mathrm{C}$ and phosphatidylinositol 3-kinase. Endocrinology 1995;136(12):5291-5297. [http://dx.doi.org/10.1210/en.136.12.5291]

2. Burguete-Garcia AI, Cruz-Lopez M, Madrid-Marina V, et al. Association of Gly972Arg polymorphism of IRS 1 gene with type 2 diabetes mellitus in lean participants of a national health survey in Mexico: A candidate gene study. Metabolism 2010;59(1):38-45. [http://dx.doi.org/10.1016/j.metabol.2009.07.007]

3. Clausen JO, Hansen T, Biørbaek C, et al. Insulin resistance: Interactions between obesity and a common variant of insulin receptor substrate-1. Lancet 1995;346:397-402. [htttp://dx.doi.org/10.1016/S0140-6736(95)92779-4]

Sesti G, Federici M, Hribal ML, et al. Defects of the insulin receptor substrate (IRS) system in human metabolic 4. Sesti G, Federici M, Hribal ML, et al. Defects of the insulin receptor substrate (IRS) syste
disorders. FASEB J 2001;15(12):2099-2111. [http://dx.doi.org/10.1096/f.01-0009rev]

5. Almind K, Inoue G, Pedersen O, Kahn CR. A common amino acid polymorphism in insulin receptor Almind $\mathrm{K}$, Inoue $\mathrm{G}$, Pedersen $\mathrm{O}$, Kahn $\mathrm{CR}$. A common amino acid polymorphism in insulin receptor
substrate-1 causes impaired insulin signaling. Evidence from transfection studies. J Clin Invest substrate-1 causes impaired insulin signaling. Evidence
1996;97(11):2569-2575. [http://dx.doi.org/10.1172/JCI118705]

6. Prudente S, Morini E, Trischitta V. Insulin signaling regulating genes: Effect on T2DM and cardiovascular risk. Nat Rev Endocrinol 2009;5:682-693. [http://dx.doi.org/10.1038/nrendo.2009.215]

7. Federici M, Pandolfi A, de Filippis EA, et al. G972R IRS-1 variant impairs insulin regulation of endothelial nitric oxide synthase in cultured human endothelial cells. Circulation 2004;109:399-405. [http://dx.doi. org/10.1161/01.CIR.0000109498.77895.6F]

8. Erasmus RT, Soita DJ, Hassan MS, et al. High prevalence of diabetes mellitus and metabolic syndrome in a South African coloured population: Baseline data of a study in Bellville, Cape Town. S Afr Med J 2012;102(11):841-844. [http://dx.doi.org/10.7196/SAMJ.5670]

9. Zemlin AE, Matsha TE, Hassan MS, Erasmus RT. HbAlc of 6.5\% to diagnose diabetes mellitus - does it work for us? - the Bellville South Africa study. PLoS One 2011;6(8):e22558. [http://dx.doi.org/10.1371/journal. pone.0022558]

10. Chalmers J, MacMahon S, Mancia G, et al. 1999 World Health Organization-International Society of Hypertension Guidelines for the Management of Hypertension. Guidelines Sub-committee of the World Health Hypertension Guidelines for the Management of Hypertension. Guidelines Sub-committee of the World Healt

11. Albanization. Clin Exp Hypertens 1999;21(5-6):1009-1060. [http://dx.doi.org/ $10.3109 / 10641969909061028$ ]
11 Zimmet PZ. Definition, diagnosis and classification of diabetes mellitus and its complications. Alberti KG, Zimmet PZ. Definition, diagnosis and classification of diabetes mellitus and its complications.
Part 1: Diagnosis and classification of diabetes mellitus provisional report of a WHO consultation. Diabet Med 1998;15(7):539-553. [http://dx.doi.org/10.1002/(SICI)1096-9136(199807)15:7\%3C539:AIDDIA668\%3E3.0.CO;2-S.

12. Friedewald WT, Levy RI, Fredrickson DS. Estimation of the concentration of low-density lipoprotein cholesterol in plasma, without use of the preparative ultracentrifuge. Clin Chem 1972;18(6):499-502.

13. Monzillo LU, Hamdy O. Evaluation of insulin sensitivity in clinical practice and in research settings. Nutr Rev 2003;61(12):397-412. [http://dx.doi.org/10.1301/nr.2003.dec.397-412]

14. Skol AD, Scott LJ, Abecasis GR, Boehnke M. Joint analysis is more efficient than replication-based analysis for two-stage genome-wide association studies. Nat Genet 2006;38:209-213. [http://dx.doi.org/10.1038/ng1706]

15. Jellema A, Zeegers MP, Feskens EJ, Dagnelie PC, Mensink RP. Gly972Arg variant in the insulin receptor substrate-1 gene and association with type 2 diabetes: A meta-analysis of 27 studies. Diabetologi 2003;46-7):990-995. [http://dx.doi.org/10.1007/s00125-003-1126-4]

16. Voight BF, Scott LJ, Steinthorsdottir V, et al. Twelve type 2 diabetes susceptibility loci identified through largescale association analysis. Nat Genet 2010;42:579-589. [http://dx.doi.org/10.1038/ng.609]

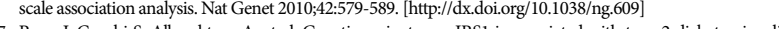
Rung J, Cauchi S, Albrechtsen A, et al. Genetic variant near IRSI is associated with type 2 diabetes, insuli resistance and hyperinsulinemia. Nat Genet 2009;41:1110-1115. [http://dx.doi.org/10.1038/ng.443]

18. Baier LJ, Hanson RL. Genetic studies of the etiology of type 2 diabetes in Pima Indians: Hunting for pieces to complicated puzzle. Diabetes 2004;53(5):1181-1186. [http://dx.doi.org/10.2337/diabetes.53.5.1181]

19. Feng X, Tucker KL, Parnell LD, et al. Insulin receptor substrate 1 (IRS1) variants confer risk of diabetes in the Boston Puerto Rican Health Study. Asia Pac J Clin Nutr 2013;22(1):150-159. [http://dx.doi.org/10.6133/ apjcn.2013.22.1.09]

20. Knowler WC, Bennett PH, Hamman RF, Miller M. Diabetes incidence and prevalence in Pima Indians: A 19fold greater incidence than in Rochester, Minnesota. Am J Epidemiol 1978;108(6):497-505.

21. Stumvoll M, Stefan N, Fritsche A, et al. Interaction effect between common polymorphisms in PPARgamma2 (Prol2Ala) and insulin receptor substrate 1 (Gly972Arg) on insulin sensitivity. J Mol Med (Berl) 2002;80(1):3338. [http://dx.doi.org/10.1007/s001090100282]

22. Kido Y, Burks DJ, Withers D, et al. Tissue-specific insulin resistance in mice with mutations in the insulin

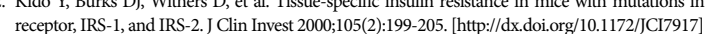

23. Deng HW. Population admixture may appear to mask, change or reverse genetic effects of genes underlying complex traits. Genetics 2001;159(3):1319-1323.

24. Lei HH, Coresh J, Shuldiner AR, Boerwinkle E, Brancati FL. Variants of the insulin receptor substrate-1 and fatty acid binding protein 2 genes and the risk of type 2 diabetes, obesity, and hyperinsulinemia in AfricanAmericans: The Atherosclerosis Risk in Communities Study. Diabetes 1999;48(9):1868-1872. [http://dx.do org/10.2337/diabetes.48.9.1868

Accepted 17 October 2013. 